\title{
Combination light-based therapies to treat pancreatic cancer: a proof of concept
}

\section{A. Ney, I. Mahamed, A. Garcia-Sampedro, P. K. Selbo, P. Sancho, et al.}

A. Ney, I. Mahamed, A. Garcia-Sampedro, P. K. Selbo, P. Sancho, A. J. MacRobert, S. P. Pereira, P. Acedo, "Combination light-based therapies to treat pancreatic cancer: a proof of concept," Proc. SPIE 11070, 17th International Photodynamic Association World Congress, 1107045 (7 August 2019); doi: 10.1117/12.2525305 


\title{
Combination light-based therapies to treat pancreatic cancer: a proof of concept
}

\author{
A. Ney ${ }^{1 *}$, I. Mahamed ${ }^{1 *}$, A. Garcia-Sampedro ${ }^{1}$, P.K. Selbo ${ }^{2}$, P. Sancho ${ }^{3}$, A.J. \\ MacRobert $^{4}$, SP. Pereira ${ }^{1}$, P. Acedo ${ }^{1,4}$ \\ ${ }^{1}$ Institute for Liver and Digestive Health, Division of Medicine, University College London, \\ UK. ${ }^{2}$ Dept. of Radiation Biology, Institute for Cancer Research, Norwegian Radium Hospital, \\ Oslo University Hospital, Norway. ${ }^{3}$ IIS Aragon, Hospital Miguel Servet, Spain. ${ }^{4}$ Division of \\ Surgery and Interventional Science, University College London, UK.
}

\section{Abstract}

Pancreatic ductal adenocarcinoma remains one of the worst types of cancers mainly due to its late diagnosis, lack of effective therapies for advance disease and high chemoresistance. Novel therapeutic options that could improve patient quality of life and overall survival are therefore imperative. In this study, we describe the use of an original strategy based on photochemical internalisation (PCI) technology for pancreatic cancer treatment. Subcellular localisation of the photosensitiser meso-tetraphenylporphine-disulfonate (TPPS 2 a) was performed in PANC-1 cells, showing its preferential accumulation in lysosomes. Treatments with increasing concentrations of the ribosome-inactivating protein saporin or TPPS ${ }_{2 \mathrm{a}}$ alone were compared with PCI-saporin. Metabolic activity and cell viability of PANC-1 cells were determined 96h post-illumination by MTT and trypan blue assays, respectively. Our results show that PCI using the photosensitiser TPPS2a, synergistically enhances the cytotoxic effects of saporin in PANC1 cells and could offer more effective treatment options for pancreatic cancer.

\section{Introduction}

Pancreatic ductal adenocarcinoma (PDAC) remains a leading cause of cancer related death despite its low incidence. Late stage diagnosis and lack of effective therapeutic options account for the high mortality rates associated with this disease. ${ }^{1-3}$ While surgical resection offers the highest chances for survival, only $20 \%$ of cases are deemed operable at time of diagnosis, out of which only around $8 \%$ will be medically fit for resection., ${ }^{3,4}$ Gemcitabine-based chemotherapy has long been used to treat both resectable and non-operable patients. However, recent studies suggest that combination chemotherapy regimens including agents such as FOLFIRINOX, GEMOXEL, nab-paclitaxel and capecitabine, can improve survival rates. The overall prognosis however, remains dismal. ${ }^{2,5,6}$

A characteristic dense, fibrotic stroma composed of a mixed population of pancreatic stellate cells, cancer associated fibroblasts, nerve cells, endothelial cells, and inflammatory cells as well as extracellular matrix components, is a hallmark of PDAC. ${ }^{7}$ This complex tumour microenvironment challenges efficient chemotherapeutic drug delivery by posing a physical barrier and reducing drug bioavailability. ${ }^{8-10}$ 
Photochemical internalisation (PCI) is a light-triggered drug delivery technique derived from Photodynamic therapy. ${ }^{11,12}$ PCI has been shown to enhance the delivery of a variety of therapeutic molecules including drugs such as doxorubicin or bleomycin, which are otherwise subject to lysosomal degradation and therefore fail to exert their full potential therapeutic effects. ${ }^{13-16}$ The successful use of Saporin-PCI in a 5- Fluorouracil chemoresistant pancreatic cancer cell line (Panc03.27) has recently reported by Lund et al. ${ }^{17}$ However, to our best knowledge, PCI of saporin has never been studied for the treatment of chemoresistant PANC1 PDAC cells.

In PCI, amphiphilic photosensitisers (PSs) that accumulate in endocytic vesicle membranes are used. Following light-mediated activation, reactive oxygen species (ROS) are generated and induce endolysosomal membrane disruption, leading to the release of the entrapped drugs into the cytosol (see Fig.1). ${ }^{18,19}$ The combined use of PSs together with therapeutic macromolecules, enables a synergistic enhancement of the cytotoxic effect and therefore, optimal drug doses can be minimised to sublethal concentrations. The fact that PSs require light illumination for their activation, ensure a site-specific induction of the cytotoxic effect which is localised to the illuminated targeted tumour area.

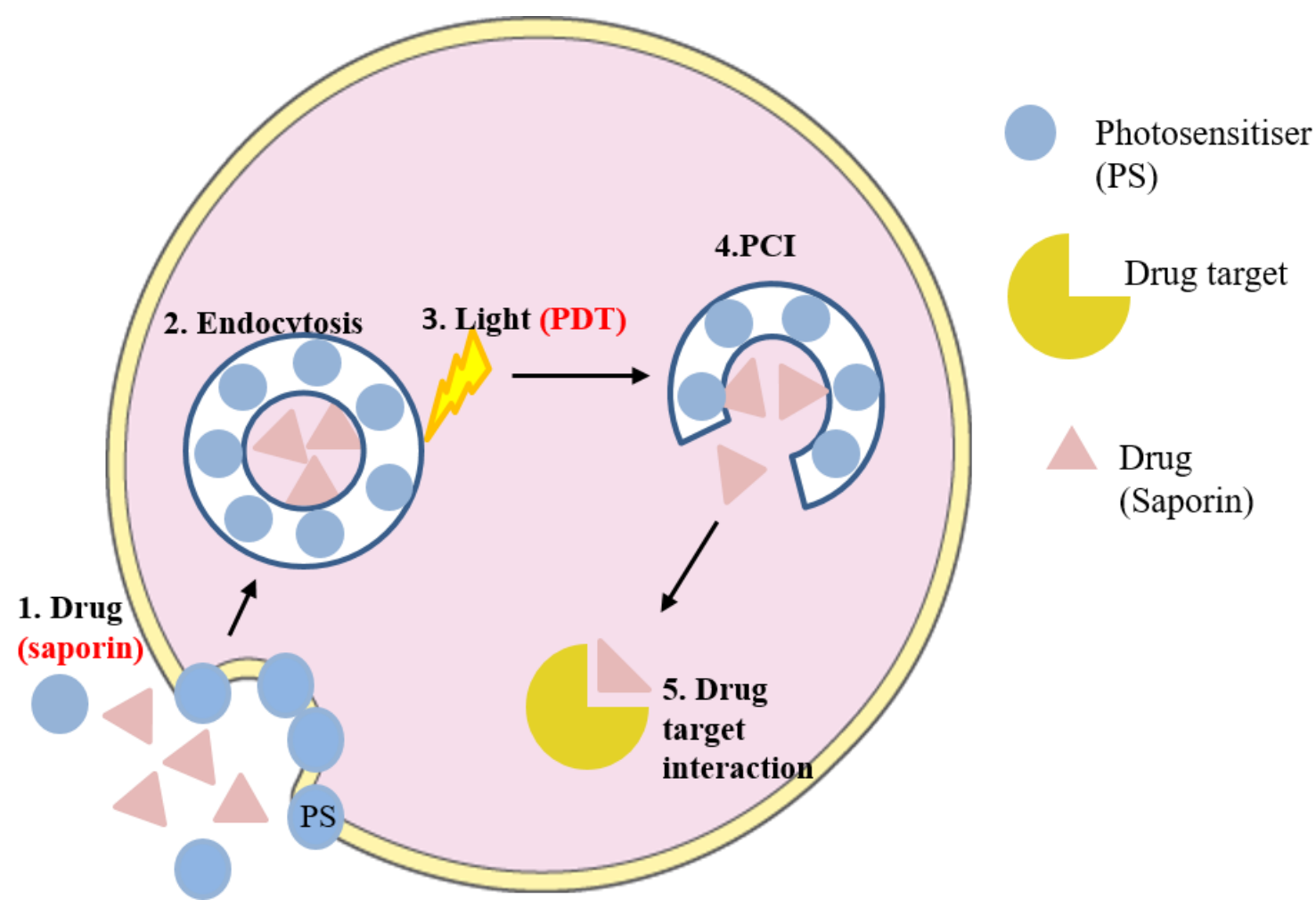

Figure 1: Principles of PCI therapy. The drug is endocytosed by the cells (1) is transported to endocytic vesicles where the PS is localised in the membrane (2). The activation of the PS by light irradiation (3) causes the disruption of the endocytic membrane (4), releasing the drug into the cytosol which can now interact with its target (5). 
Type-I ribosome-inactivating proteins (RIPs) are attractive PCI agents as they enter into the cells via endocytosis, and are further transported to the lysosomes for degradation. ${ }^{20-22}$ In this study we present our encouraging results of the synergistic augmentation of the cell killing effect of saporin, (a type I RIP isolated from the seeds of the plant Saponaria officinalis, commonly known as Soapwort), together with TPPS2a in an in vitro model of PDAC. These studies are a proof of concept to support further experimental work using more clinically relevant chemotherapeutic agents and PDAC models.

\section{$\underline{\text { Methodology }}$}

\section{Cell culture}

The gemcitabine resistant PDAC cell line PANC-1 (ATCC® CRL-1469' ${ }^{\mathrm{TM}}$ ) was used in this study. Cells were grown in $75 \mathrm{~cm}^{2}$ tissue culture flasks (TPP, Switzerland) and were cultured in DMEM (Dulbecco's Modified Eagle's Medium, Sigma Aldrich, UK) supplemented with 10\% fetal bovine serum (FBS) (Gibco, UK) and 1\% Penicillin-Streptomycin (Gibco, UK). Cells were kept in a BINDER incubator (Tuttlingen, Germany) at $37^{\circ} \mathrm{C}$ in $95 \%$ humidity and $5 \%$ $\mathrm{CO}_{2}$. Once a confluence of $70 \%$ was reached, cells were either sub-cultured or seeded for the below described protocols.

\section{Spectroscopic studies of TPPS $_{2 \mathrm{a}}$}

The absorption and emission spectra of the amphiphilic photosensitiser TPPS $2_{\mathrm{a}}$ in methanol (Fig. 2a and 2b) were analysed using a Jasco V-630 UV (Jasco, UK) spectrophotometer and a Spex Fluoromax-4 spectrofluorometer (Horiba Jobin-Ybon, USA) respectively, according to manufacturer guidelines.

\section{Sub-cellular localisation of TPPS $_{2 a}$ using fluorescence microscopy}

We investigated the subcellular localisation of TPPS $_{2 a}$ by fluorescence microscopy. To corroborate its accumulation into lysosomes the lysosomal probe, LysoTracker ${ }^{\circledR}$ Green DND 26 (Life technologies ${ }^{\mathrm{TM}}$ ) was used. A Leica DMI4000b inverted fluorescence microscope was used for image acquisition ((excitation light wavelengths used were $405 \mathrm{~nm}$ (TPPS ${ }_{2 \mathrm{a}}$ ) and 488nm (LysoTracker Green)) at 60X magnification.

\section{TPPS $_{2 \mathrm{a}}$ redistribution following light exposure}

$\mathrm{TPPS}_{2 \mathrm{a}}$ redistribution following light exposure was studied using an Olympus IMT-2 epifluorescence inverted microscope with 20X and 60X magnification objectives. Cells were seeded onto FluoroDishTM (World Precision Instruments, Inc.) glass bottom dishes at 20,000 cell/dish density. Cells were incubated with TPPS $_{2 \mathrm{a}}$ for $18 \mathrm{~h}$ and the control group only supplemented with culture media. Following incubation with TPPS2a, the plates were washed twice using PBS, fresh media was added and fluorescence was immediately analysed. A $2 \mathrm{~mW}$ $405 \mathrm{~nm}$ blue diode laser module (Thorlabs Inc.) was used for TPPS ${ }_{2 \mathrm{a}}$ excitation. Images prior to excitation and at timed intervals ( 3 and 5 minutes) after light illumination were captured using a 512x512 pixel cooled charge-coupled device (CCD) camera (PIXIS 512F, Princeton Instruments Inc.) using a $660 \mathrm{~nm}$ bandpass detection filter (Omega Optical Inc.). 


\section{MTT assay}

The 3-(4,5-dimethylthiazol-2-yl)-2,5-diphenyltetrazolium bromide (MTT) colorimetric cell viability assay was used to assess the $\%$ of reduction in cell viability (metabolic activity) achieved at different times after the end of the treatments. An absorbance microplate reader (ELx800 BioTek, UK) was used to detect optical density at 562nm. MTT assays were performed at $48 \mathrm{~h}$ and $96 \mathrm{~h}$ time intervals following treatment.

\section{Saporin and TPPS2a monotherapies dose response analysis}

In order to investigate the possible cytotoxic effects induced by saporin or TPPS $2 \mathrm{a}$ monotherapies (Fig. 2c), as well as determine the optimal doses for further experiments, PANC-1 cells were treated with increasing concentrations of saporin $(0.1-80 \mathrm{nM})$ or TPPS $_{2 \mathrm{a}}$ $(0.05-0.8 \mu \mathrm{g} / \mathrm{ml})$ for $18 \mathrm{~h}$. In the case of TPPS $_{2 \mathrm{a}}$ treatments, two illumination time intervals were used 3 or $5 \mathrm{~min}$ corresponding to 1.26 and $2.1 \mathrm{~J} / \mathrm{cm}^{2}$ light doses, respectively. The illumination of the samples was performed using a LumiSource Lamp (PCI Biotech, Norway). The spectrum of the blue light ranges between 375-450nm with a peak wavelength at approximately $420 \mathrm{~nm}$ (fluence rate: $7 \mathrm{~mW} / \mathrm{cm}^{2}$ ). Studies were also performed in the dark (without light illumination) to validate the light-mediate induction of cell toxicity.

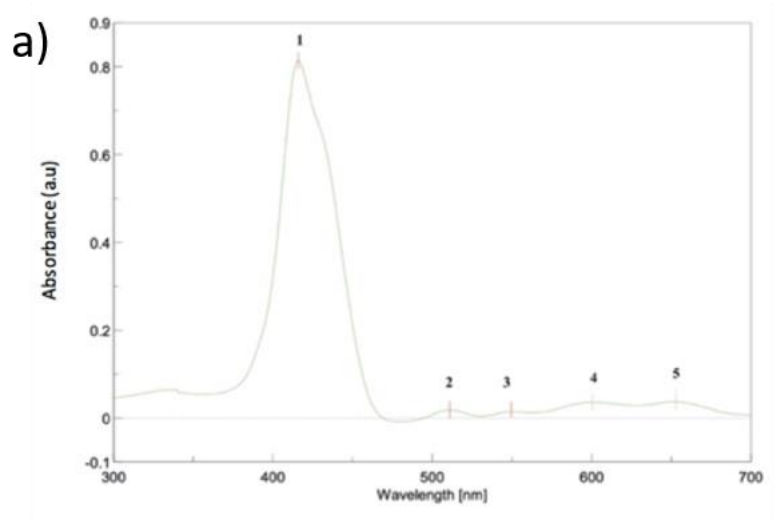

b)
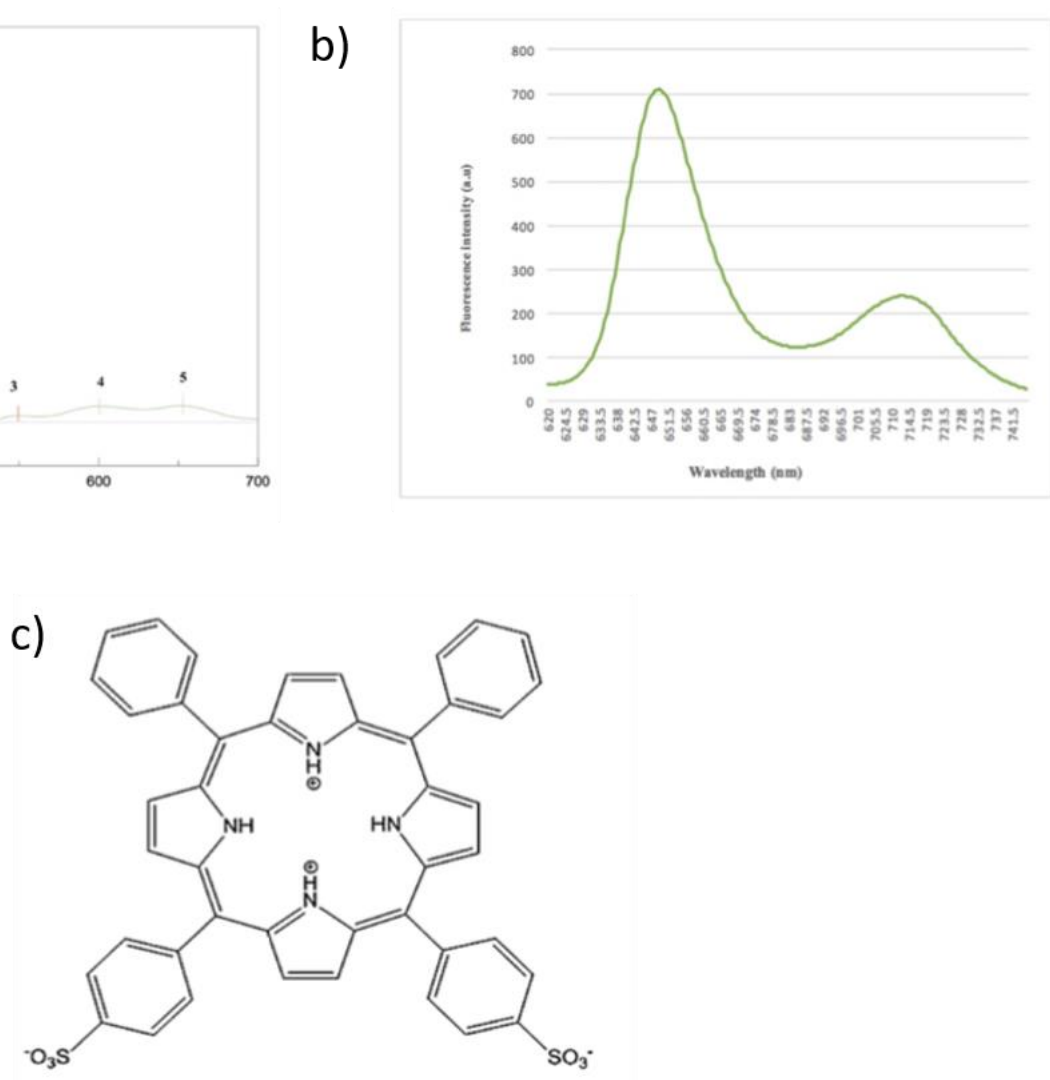

Figure 2. a) Chemical structure of $\operatorname{TPPS}_{2 \mathrm{a}}{ }^{23} \mathrm{~b}$ ) $\mathrm{TPPS}_{2 \mathrm{a}}$ absorption spectra in methanol. A major absorption peak was observed at $416 \mathrm{~nm}$ (corresponding to the Soret band) and 4 smaller ( $\mathrm{Q}$ band) peaks (2-5) were seen closer to the near red region of the spectra. c) TPPS $2 \mathrm{a}$ fluorescence emission spectra. TPPS2a excitation achieved using a $415 \mathrm{~nm}$ wavelength. Two fluorescence emission peaks $(650 \mathrm{~nm}$ and $715 \mathrm{~nm})$ were detected. 


\section{Photochemical internalisation protocols}

The effects of saporin-PCI (saporin + TPPS $_{2 a}+$ light combination protocol) in PANC-1 proliferation capacity were assessed 48 and $96 \mathrm{~h}$ following treatment using the MTT assays. Optimal drug concentrations were chosen based on the monotherapy dose response experiments. The following experimental groups were established: control (untreated cells), saporin only (saporin monotherapy: 10,20 or $40 \mathrm{nM}$ ), PS only (TPPS 2 monotherapy: 0.1 or $0.2 \mu \mathrm{g} / \mathrm{ml}$ ) and combination (PCI groups). After an $18 \mathrm{~h}$ treatment, cells were illuminated with blue light for 1.26 and $2.1 \mathrm{~J} / \mathrm{cm}^{2}$ total light doses. One plate was not exposed to light and defined as "dark toxicity" control group. MTT assays were performed $48 \mathrm{~h}$ and $96 \mathrm{~h}$ after illumination.

\section{Validation of reduction in cell viability and induction of cell death following PCI using the trypan blue dye exclusion test}

Morphological tests and analysis of cell viability using the Trypan Blue (TB) dye exclusion test, were performed following monotherapies and PCI protocols to determine whether the reduction in cell viability observed by MTT assays was due to inhibition of cell proliferation (cell cycle arrest) or due to induction of cell death. TB test was performed 24, 48 and 96h after treatment. An EVOS (Thermo Fisher Scientific) inverted microscope was used to analyse cell morphology and dye uptake at the above mentioned timepoints.

\section{Assessment of the effects of combination treatments}

The effects of combined treatments using saporin and the TPPS 2 a were assessed for synergism after PCI protocols using the Valeriote and Lin method. ${ }^{24,25}$ When: $[A+B]<[A] X[B] / 100$ the interaction is synergistic (where $[\mathrm{A}+\mathrm{B}]$ - cell viability following $\mathrm{PCI},[\mathrm{A}]-$ cell viability following saporin treatment, [B]- cell viability following TPPS $_{2 \mathrm{a}}$ treatment).

\section{Statistical analysis}

All experiments were repeated at least three times for statistical accuracy. Raw data using mean average of optical densities was normalised against control data and analysed with Prism 7.0 statistical analysis software. An independent t-test and a One-way ANOVA test were applied, where two groups and three (or more) independent groups were compared, respectively. A significance level of $<0.05$ was set for all experiments in order to determine significant difference between groups. P-values are represented in graphs as follows: p-value <0.05 = *; p $<0.01=* * ; \mathrm{p}<0.001=* * *$.

\section{Results}

\section{Absorption and emission spectra of TPPS 2 a}

Absorption spectra analysis demonstrated a major absorbance peak (the Soret band) at 416nm within the blue light spectrum (Fig. 2a) and further four minor (Q band) absorption peaks at $511 \mathrm{~nm}, 550 \mathrm{~nm}, 600.5 \mathrm{~nm}$, and $652.5 \mathrm{~nm}$ in the near red region of the spectra (Fig. 2a peaks 2- 
5, respectively). Fluorescence analysis using spectrofluorometry showed two emission peaks following TPPS $_{2 \mathrm{a}}$ excitation at $405 \mathrm{~nm}$. The first emission peak was observed at $650 \mathrm{~nm}$ while the second emission peak at 715nm (Fig. 2b).

\section{TPPS2a localises in the lysosomes of PANC-1 cells}

The subcellular localisation of TPPS 2 a within PANC-1 cells was analysed using fluorescence microscopy. Excitation of the PS using a 405nm wavelength yielded intense red fluorescence emission with an intracellular granular pattern of distribution, suggesting uptake into endosomes and lysosomes (Fig. 3a). Detection of the specific endosomal/lysosomal (acidic organelles) probe LysoTracker Green DND26 (green fluorescence) confirmed TPPS $2 \mathrm{a}$ internalisation and accumulation in endosomes/lysosomes as apparent in the same figure when the overlap between the red and green channels was made (yellow fluorescence).

\section{TPPS $_{2 \mathrm{a}}$ is redistributed from the endosomes/lysosomes to the cytoplasm following light exposure}

Following confirmation of TPPS $_{2 a}$ internalisation and subcellular localisation within lysosomes, the redistribution of this PS after light excitation was studied. Images were acquired using an epi-fluorescence wide field microscope, subsequent to $\operatorname{TPPS}_{2 \mathrm{a}}$ light excitation at a wavelength of $405 \mathrm{~nm}$. A similar intracellular granular pattern of TPPS $_{2 a}$ distribution in lysosomes was observed prior to light excitation (Fig. 3b), confirming our previous findings. Five minutes following light exposure, the distribution pattern of $\operatorname{TPPS}_{2 \mathrm{a}}$ became diffuse (Fig. 3b) compared to images taken immediately following light exposure (Fig. 3b), demonstrating $\mathrm{TPPS}_{2 \mathrm{a}}$ redistribution within the cell. No fluorescence was detected in PANC-1 control cells that were not incubated with $\operatorname{TPPS}_{2 \mathrm{a}}(\mathbf{F i g} \mathbf{3 b})$.

a)

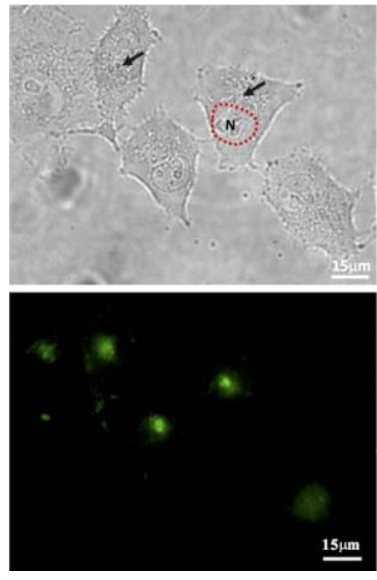

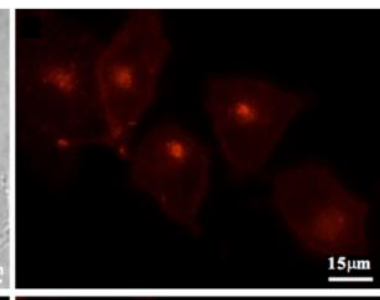

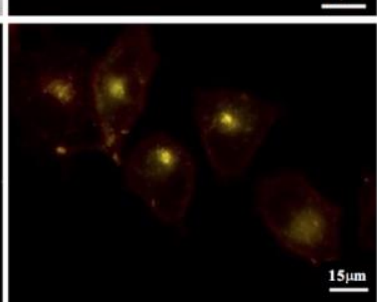

b)
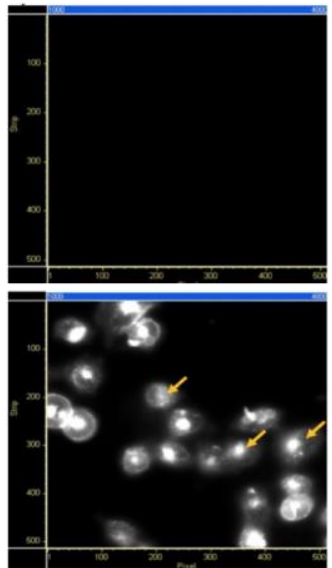
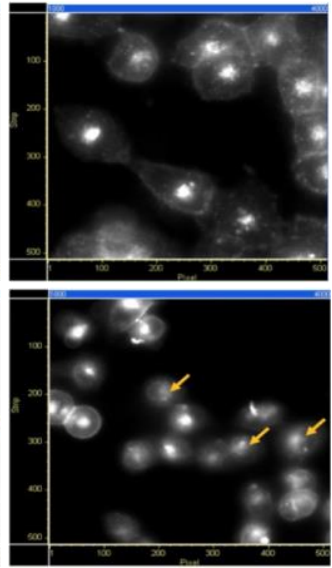

Figure 3. a) Subcellular accumulation of TPPS 2 a in endolysosomes of PANC-1 cells analysed by fluorescence microscopy (60X magnification). Cells were incubated with $1 \mu \mathrm{g} / \mathrm{ml}$ TPPS $_{2 \mathrm{a}}$ for $18 \mathrm{~h}$. 50nM LysoTracker Green was added $1 \mathrm{~h}$ prior to imaging. 60X magnification light microscope (top left) (N-nucleus, black arrows mark endolysosome location adjacent to the nucleus). TPPS 2 a distribution (red fluorescence). Lysotracker green staining lysosomes in green. Merged image of TPPS $2 \mathrm{a}$ (red) and Lysotracker (green) fluorescence giving a yellow fluorescence pattern (bottom right image). Scale bar: $15 \mu \mathrm{m} . \mathrm{b}$ ) 
Subcellular redistribution of TPPS 2 a following light exposure. Control cells (not treated) (top left). Images acquired using an Olympus IMT-2 epi-fluorescence inverted microscope demonstrated intracellular localisation of TPPS 2 (top right) in a granular pattern in lysosomes, while no signal was detected in the untreated control cells (top left image). TPPS $2 \mathrm{a}$ redistribution within the cytoplasm (marked by arrows) was observed 5 minutes following blue illumination (bottom right image), compared to images acquired immediately after light exposure (bottom left). Images were taken with a $60 \mathrm{X}$ (top row) and 20X magnification objectives (bottom row) using a 250X250 micron scale.

\section{High concentrations of saporin and TPPS $_{2 a}$ are needed to inactivate PANC-1 cells when used as monotherapies}

The optimal saporin concentration for PCI experiments as well as its cytotoxic effect on PANC-1 cells, were determined after cell incubation with increasing concentrations of saporin (0.1-80nM). Results of MTT assays performed 48 and $96 \mathrm{~h}$ following each treatment are represented in Figure $4 \mathbf{a}$ by means of \% survival. A statistically significant cytotoxicity was observed only when using saporin concentrations higher than 40nM, suggesting dose dependent cytotoxicity. A statistically significant reduction in cell viability was observed with $60 \mathrm{nM}(\mathrm{p}$-value $=0.04)$ and $80 \mathrm{nM}(\mathrm{p}$-value $=0.03)$ only in the $96 \mathrm{~h}$ experiments, when compared to control cells (not treated). Saporin concentrations of 10, 20 and 40nM were chosen for further PCI experiments as sub-lethal concentrations of the drug to minimise systemic side effects.

No significant toxicity was observed in the TPPS $_{2 \mathrm{a}}$-treated but non-illuminated (0min/dark) cells compared to the control group, regardless of the concentrations used, confirming the absence of dark toxicity and safety of the photosensitiser (data not shown). Time- and concentration-dependent increase of cell toxicity was observed at both $48 \mathrm{~h}$ (data not shown) and 96h (Fig. 4b). A significant reduction $(\mathrm{p}<0.001)$ in cell proliferation was detected with a concentration as low as $0.1 \mu \mathrm{g} / \mathrm{ml}$ TPPS $_{2 \mathrm{a}}$ following $3 \mathrm{~min}$ light exposure $(10 \%$ reduction compared to untreated control cells). Treatment using a TPPS 2 a concentration of $0.2 \mu \mathrm{g} / \mathrm{ml}$, resulted in a reduction of cell proliferation of $32 \%$ and 54\% following 3- and 5min illumination in the $48 \mathrm{~h}$ plates, and $29 \%$ and $67 \%$ following $3-$ and 5-min illumination, respectively, in the $96 \mathrm{~h}$ plates. Using TPPS $2_{\text {a }}$ concentrations of $0.3 \mu \mathrm{g} / \mathrm{ml}$ or higher, $80-90 \%$ reduction in proliferation was detected. Similarly, near complete cell inactivation was observed at these concentrations in the $96 \mathrm{~h}$ plates.

\section{PCI protocols induced a synergistic growth inhibition and cell death of pancreatic cancer cells}

Analysis of the PCI effect in PANC-1 cell proliferation using 10, 20, and 40nM saporin together with 0.1 or $0.2 \mu \mathrm{g} / \mathrm{ml}$ TPPS $_{2 \mathrm{a}}$ were compared to saporin and TPPS 2 monotherapies at 48 and $96 \mathrm{~h}$ following treatment (Fig. 4c). PCI enhanced the cytosolic delivery of saporin and its effect was increased as a function of illumination time and saporin concentration. At 96h post treatment, a more pronounced augmentation of the PDT effect was observed and therefore only these will be described below.

No toxicity was observed in the PCI plates that were not exposed to illumination (data not shown). PCI effect using combinations of saporin $10 \mathrm{nM}$ with 0.1 or $0.2 \mu \mathrm{g} / \mathrm{ml}$ TPPS $_{2 \mathrm{a}}$, resulted in significant cell viability reduction compared to monotherapies (Fig. 4c). With three-minute light exposure $\left(1.26 \mathrm{~J} / \mathrm{cm}^{2}\right)$, PCI using $0.1 \mu \mathrm{g} / \mathrm{ml} \mathrm{TPPS}_{2 \mathrm{a}}+10 \mathrm{nM}$ saporin 
decrease in cell viability, while an increase in $\operatorname{TPPS}_{2 \mathrm{a}}$ concentration to $0.2 \mu \mathrm{g} / \mathrm{ml}$, resulted in a $59 \%$ reduction $48 \mathrm{~h}$ after the end of the treatment. Compared to PDT alone $\left(\mathrm{TPPS}_{2 \mathrm{a}}\right.$ monotherapy), a significant augmentation of the cytotoxic effect was demonstrated in both cases using PCI, with a $2.7(\mathrm{p}<0.001)$ and $1.7(\mathrm{p}<0.001)$ fold increase in effect respectively. Maximal reduction in cell viability was seen when cells were illuminated for five minutes (2.1 $\mathrm{J} / \mathrm{cm} 2$ light dose), achieving $51 \%$ and $77 \%$ cell killing effect for $10 \mathrm{nM}$ saporin with $0.1 \mu \mathrm{g} / \mathrm{ml}$ and $0.2 \mu \mathrm{g} / \mathrm{ml}$, respectively. PCI using $0.1 \mu \mathrm{g} / \mathrm{ml}$ TPPS $_{2 \mathrm{a}}$ showed a 2.1 -fold increase $(\mathrm{p}<0.001)$ in cell killing effect compared to PDT alone (TPPS $2 \mathrm{a}$ monotherapy), at this concentration of TPPS $_{2 \mathrm{a}}$. The use of $0.2 \mu \mathrm{g} / \mathrm{ml}$ together with saporin $10 \mathrm{nM}$, led to a 1.4 -fold augmentation of the PDT effect at this concentration of PS $(\mathrm{p}<0.001)$. No increase in cell proliferation (suggesting cell recovery after treatment) was observed $96 \mathrm{~h}$ following the PCI treatment. This fact could be explained by an efficient induction of either cell cycle arrest or cell death following PCI.

In order to determine whether PCI using higher concentrations of saporin results in greater enhancement of the effect achieved using TPPS $_{2 \mathrm{a}}$ alone, $20 \mathrm{nM}$ and $40 \mathrm{nM}$ of saporin were tested next. PCI using 20 or 40nM of saporin did not result in a significant reduction in cell viability compared to PCI using 10nM (and therefore this data has not been included in this manuscript). However, PCI with 40nM of saporin resulted in significantly higher enhancement of the PDT effect. A factor of 4.65 was the highest enhancement of PDT effect (PCI\%reduction in cell viability/PDT $\%$ reduction in cell viability) observed in this study, where $0.1 \mu \mathrm{g} / \mathrm{ml}$ TPPS2a was used together with 40nM saporin, subject to 3-minute light exposure, 96h after treatment. A $46.5 \%$ reduction in viability with PCI compared to $10 \%$ with PDT was observed.

In all cases, the use of PCI showed a synergistic effect over PDT (TPPS 2 monotherapy) and saporin monotherapies. This was determined using the Valeriote and Lin method of assessing synergism in anticancer treatments ${ }^{24}$ and is detailed in Table $\mathbf{1 .}$

Table 1. The synergistic effect of PCI over TPPS 2 and saporin monotherapies as a function of treatment doses and illumination time, was assessed using the Valeriote and Lin method. In brief, if $[\mathbf{A}+\mathbf{B}]<[\mathbf{A}] \mathbf{X}[\mathbf{B}] / \mathbf{1 0 0}$ the interaction is synergistic. A= cell viability after TPPS $_{2 a}$ treatment; $B=$ cell viability after saporin monotherapy, $[A+B]=$ cell viability after PCI. PCI shows a clear synergistic effect when TPPS $2 \mathrm{a}$ is combined with saporin.

\begin{tabular}{|c|c|c|c|c|}
\hline \multirow{3}{*}{ Illumination time } & $\begin{array}{c}|c| \\
\text { Treatment dose } \\
\text { TPPS }_{2 \mathbf{a}}+\text { +saporin }\end{array}$ & {$[\mathbf{A}+\mathbf{B}]$} & [A]X[B]/100 & Effect \\
\hline \multirow{3}{*}{3} & $0.1 \mu \mathrm{g} / \mathrm{ml}+10 \mathrm{nM}$ & 60 & 83 & Synergistic \\
\cline { 2 - 5 } & $0.2 \mu \mathrm{g} / \mathrm{ml}+10 \mathrm{nM}$ & 27 & 60 & Synergistic \\
\cline { 2 - 5 } & $0.1 \mu \mathrm{g} / \mathrm{ml}+40 \mathrm{nM}$ & 54 & 86 & Synergistic \\
\cline { 2 - 5 } & $0.2 \mu \mathrm{g} / \mathrm{ml}+40 \mathrm{nM}$ & 18 & 67 & Synergistic \\
\hline \multirow{2}{*}{5 minutes } & $0.1 \mu \mathrm{g} / \mathrm{ml}+10 \mathrm{nM}$ & 46 & 63 & Synergistic \\
\hline
\end{tabular}




\begin{tabular}{|c|c|c|c|c|}
\hline & $0.2 \mu \mathrm{g} / \mathrm{ml}+10 \mathrm{nM}$ & 7 & 32 & Synergistic \\
\cline { 2 - 5 } & $0.1 \mu \mathrm{g} / \mathrm{ml}+40 \mathrm{nM}$ & 33 & 65 & Synergistic \\
\cline { 2 - 5 } & $0.2 \mu \mathrm{g} / \mathrm{ml}+40 \mathrm{nM}$ & 5 & 40 & Synergistic \\
\hline
\end{tabular}

The trypan blue (TB) cell-death assay analysis $24 \mathrm{~h}$ following treatment did not show any significant morphological changes neither significant TB uptake and therefore is not further described. Images were acquired $48 \mathrm{~h}$ or $96 \mathrm{~h}$ following incubation with saporin only $(10,20$ or $40 \mathrm{nM}$ ), treatment using $0.1 \mu \mathrm{g} / \mathrm{ml}$ or $0.2 \mu \mathrm{g} / \mathrm{ml} \mathrm{TPPS}{ }_{2 \mathrm{a}}$ subject to 3- or 5-minute illumination or PCI combination therapy. A higher ratio of TB uptake and reduction in cell density was observed as a function of increased concentrations of saporin, $\operatorname{TPPS}_{2 \mathrm{a}}$ and illumination time following PDT and to a higher extent, after PCI. Cytotoxicity was clearly enhanced when PCI therapy using $40 \mathrm{nM}$ and $0.2 \mu \mathrm{g} / \mathrm{ml}$ TPPS $_{2 \mathrm{a}}$ was applied (see Fig. 4d). This effect correlates with the reduction in cell viability observed and described previously following MTT assays. Analysis performed 96h following PDT and PCI treatment demonstrated the highest cytotoxic effects. Cells that were subject to 5 minutes of light exposure showed a higher degree of cell detachment and cell death following PCI treatments. All detached cells after PCI therapy were positive for trypan blue staining indicating a loss of plasma membrane integrity after treatment and induction of cell death.

a)

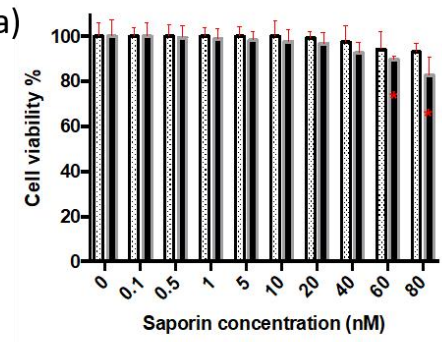

c)

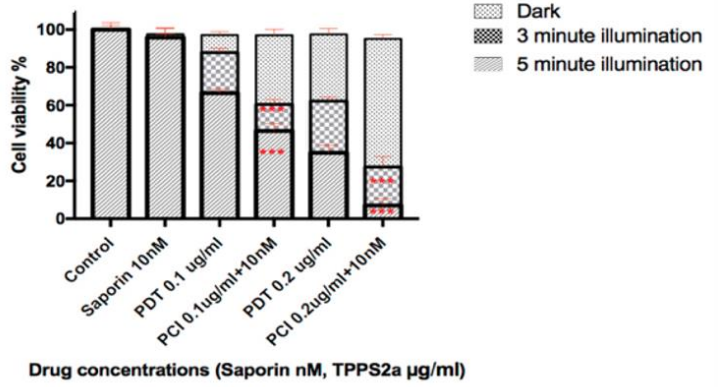

b)

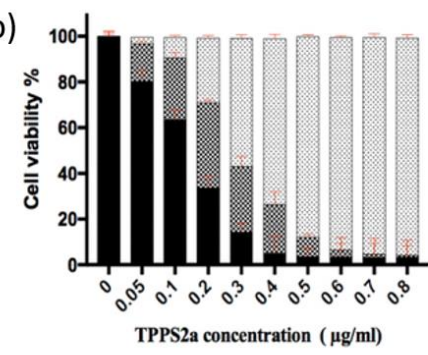

d)

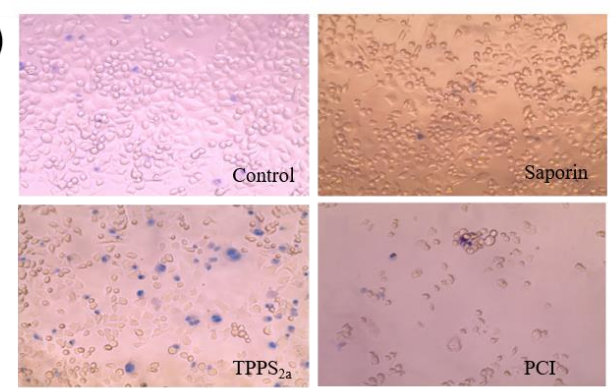

Figure 4. a) Saporin dose response 48h and 96h after the end of the treatment. Dose dependent toxicity was observed over $40 \mathrm{nM}$ saporin. b) TPPS $2 \mathrm{a}$ dose response analysis performed $96 \mathrm{~h}$ after illumination. Cells were treated with increasing concentrations of photosensitiser for 18h. Two illumination times were tested: 3 and $5 \mathrm{~min}$ (corresponding to 1.26 and 2.1 
$\mathrm{J} / \mathrm{cm}^{2}$ respectively). c) PCI effect of $10 \mathrm{nM}$ saporin combined with 0.1 or $0.2 \mu \mathrm{g} / \mathrm{ml} \mathrm{TPPS}_{2 \mathrm{a}}$ analysed $96 \mathrm{~h}$ after the end of the treatment. Cell viability is expressed as percentage of survival compared to control (not treated cells). Error bars represent standard deviations. Statistically significant differences observed between groups are expressed as follows: $\mathrm{p}$-value $<0.05=*$; $\mathrm{p}<0.01=* * ; \mathrm{p}<0.001=* * *$ d) Trypan blue assay analysed at $96 \mathrm{~h}$ following treatment subsequent to three-minute light exposure $\left(2.1 \mathrm{~J} / \mathrm{cm}^{2}\right)$. Control cells (top left). Cells treated with saporin 40nM only (top right), showing minimal TB uptake (viable cells). Cells treated with $0.2 \mu \mathrm{g} / \mathrm{ml}$ TPPS $_{2 a}$ monotherapy (bottom left), showed a higher degree of reduction in cell density as well as of dye uptake. PCI combining $40 \mathrm{nM}$ of saporin and $0.2 \mu \mathrm{g} / \mathrm{ml} \mathrm{TPPS}_{2 \mathrm{a}}$ resulted in significant reduction in cell adhesion and subsequent cell death induction (bottom right).

\section{Conclusions}

We successfully demonstrated the uptake of the photosensitiser TPPS ${ }_{2 a}$ by PANC-1 cells and its accumulation into endolysosomes as an essential requirement for its use in PCI. Additionally, we demonstrated redistribution of $\mathrm{TPPS}_{2 \mathrm{a}}$ subsequent to light exposure in line with lysosomal disruption. Saporin monotherapy induced minimal toxicity to PANC-1 cells while TPPS $_{2 a}$ alone demonstrated a concentration and light dose dependent toxic effect. Remarkably, the combination of saporin + TPPS $_{2 a}+$ light (PCI protocol) in sub-lethal doses, resulted in almost a five-fold increase in the cytotoxic effect compared to both monotherapies. At the same time, PCI enhanced the cytosolic delivery of saporin and its effect was increased as a function of illumination time and saporin concentration. Altogether our results suggest that $\mathrm{TPPS}_{2 \mathrm{a}}$-PCI of cytotoxic drugs such as saporin achieves a synergistic effect greater than single therapies being more effective in inactivating chemo-resistant pancreatic cancer cells. Further analysis involving clinically approved chemotherapeutic agents and more complex biological models are needed but, PCI has shown promise as a possible novel pancreatic cancer therapy.

\section{REFERENCES}

[1] Garrido-Laguna, I. and Hidalgo, M., "Pancreatic Cancer: From State-of-the-Art Treatments to Promising Novel Therapies." Nature Reviews Clinical Oncology 12(6), 319-34 (2015).

[2] Kleeff, J., Korc, M., Apte, M.,La Vecchia, C., Johnson, C.D., Biankin, A.V., Neale, R.E., Tempero, M., Tuveson, D.A., Hruban, R.H., and Neoptolemos, J.P.. "Pancreatic Cancer." Nature Reviews. Disease Primers 2, 16022 (2016).

[3] Rombouts, S. J. E., Vogel, J.A., van Santvoort, H.C., van Lienden, K.P., van Hillegersberg, R., Busch, O.R.C., Besselink, M.G. H., and Molenaar, I.Q.. "Systematic Review of Innovative Ablative Therapies for the Treatment of Locally Advanced Pancreatic Cancer." British Journal of Surgery 102(3), 182-93 (2015).

[4] CRUK. 2017. “Cancer Research UK: Pancreatic Cancer.” Retrieved June 25, 2019 (https://www.cancerresearchuk.org/about-cancer/pancreatic-cancer/survival).

[5] Swayden, M., Iovanna, J., and Soubeyran, P. "Pancreatic Cancer Chemo-Resistance Is Driven by Tumor Phenotype Rather than Tumor Genotype." Heliyon 4(12) (2018). 
[6] Chin, V., Nagrial, A., Sjoquist, K., O’Connor, C.A., Chantrill, L., Biankin, A.V., Scholten, R.J.P.M. and Yip, D. "Chemotherapy and Radiotherapy for Advanced Pancreatic Cancer." Cochrane Database of Systematic Reviews (3) (2018).

[7] Neesse, A., Bauer, C.A., Ohlund, D., Lauth, M., Buchholz, M., Michl, P., Tuveson, D.A., and Gress, T.M. "Stromal Biology and Therapy in Pancreatic Cancer: Ready for Clinical Translation?" Gut 68(1), 159-71 (2019).

[8] Schober, M., Jesenofsky, R., Faissner, R., Weidenauer, C., Hagmann, W., Michl, P., Heuchel, R.L., Haas, S.L., and Lohr, J.M.. "Desmoplasia and Chemoresistance in Pancreatic Cancer." Cancers 6(4), 2137-54 (2014).

[9] Chand, S., O'Hayer, K., Blanco, F.F., Winter, J.M., and Brody, J.R. "The Landscape of Pancreatic Cancer Therapeutic Resistance Mechanisms.” International Journal of Biological Sciences 12(3), 27382 (2016).

[10] Nielsen, M.F.B., Mortensen, M.B., and Detlefsen, S. "Key Players in Pancreatic Cancer-Stroma Interaction: Cancer-Associated Fibroblasts, Endothelial and Inflammatory Cells." World Journal of Gastroenterology 22(9), 2678-2700 (2016).

[11] Selbo, P.K., Bostad, M., Olsen, C.E., Edwards, V.T., Hogset, A., Weyergang A., and Berg, K. "Photochemical Internalisation, a Minimally Invasive Strategy for Light-Controlled Endosomal Escape of Cancer Stem Cell-Targeting Therapeutics." Photochemical \& Photobiological Sciences 14(8), 1433-50 (2015).

[12] Bayona, A. M. de P., Moore, C. M., Loizidou, M., MacRobert, A.J., and Woodhams, J.H. "Enhancing the Efficacy of Cytotoxic Agents for Cancer Therapy Using Photochemical Internalisation.” International Journal of Cancer 138(5), 1049-57 (2016).

[13] Arentsen, H. C., Falke, J., Hogset, A., Oosterwijk, E., and Witjes, J.A. "The Effect of Photochemical Internalization of Bleomycin in the Treatment of Urothelial Carcinoma of the Bladder: An in Vitro Study.” Urologic Oncologic-Seminars and Original Investigations 32(1) (2014).

[14] Sultan, A.A., Jerjes, W., Berg, K., Hogset, A., Mosse, C.A., Hamoudi, R., Hamdoon, Z., Simeon, C., Carnell, D., Forster, M., and Hopper, C. "Disulfonated Tetraphenyl Chlorin (TPCS2a)Induced Photochemical Internalisation of Bleomycin in Patients with Solid Malignancies: A Phase 1, Dose-Escalation, First-in-Man Trial.” Lancet Oncology 17(9), 1217-29 (2016).

[15] Shin, D., Christie, C., Ju, D., Nair, R.K., Molina, S., Berg, K., Krasieva, T.B., Madsen, S.J. and Hirschberg, H. "Photochemical Internalization Enhanced Macrophage Delivered Chemotherapy." Photodiagnosis and Photodynamic Therapy 21, 156-62 (2018).

[16] Eng, M. S., Kaur, J., Prasmickaite, L., Engesaeter, B.O., Weyergang, A., Skarpen, E., Berg, K., Rosenblum, M.G., Maelandsmo, G.M., Hogset, A., Ferrone, S., and Selbo, P.K. "Enhanced Targeting of Triple-Negative Breast Carcinoma and Malignant Melanoma by Photochemical Internalization of CSPG4-Targeting Immunotoxins.” Photochemical and Photobiological Sciences 17(5), 539-51 (2018).

[17] Lund, K., Olsen, C.E., Wong, J.J.W., Olsen, P.A., Solberg, N.T., Hogset, A., Krauss, S. and Pal, P.K. "5-FU Resistant EMT-like Pancreatic Cancer Cells Are Hypersensitive to Photochemical 
Internalization of the Novel Endoglin-Targeting Immunotoxin CD105-Saporin.” Journal of Experimental \& Clinical Cancer Research 36 (2017).

[18] Selbo, P.K., Weyergang, A., Hogset, A., Norum, O.J., Berstad, M.B., Vikdal, M., and Berg, K. "Photochemical Internalization Provides Time- and Space-Controlled Endolysosomal Escape of Therapeutic Molecules.” Journal of Controlled Release 148(1, SI), 2-12 (2010).

[19] O’Rourke, C., Hopper, C., MacRobert, A.J., Phillips, J.B., and Woodhams, J.H. "Could Clinical Photochemical Internalisation Be Optimised to Avoid Neuronal Toxicity?" International Journal of Pharmaceutics 528(1-2), 133-43 (2017).

[20] Stratford, E.W., Bostad, M., Castro, R., Skarpen, E., Berg, K., Hogset, A., Myklebost, O., and Selbo, P.K.. "Photochemical Internalization of CD133-Targeting Immunotoxins Efficiently Depletes Sarcoma Cells with Stem-like Properties and Reduces Tumorigenicity." Biochimica et Biophysica Acta-General Subjects 1830(8), 4235-43 (2013).

[21] Selbo, P. K., Sandvig, K., Kirveliene, V., and Berg, K. "Release of Gelonin from Endosomes and Lysosomes to Cytosol by Photochemical Internalization." Biochimica et Biophysica ActaGeneral Subjects 1475(3), 307-13 (2000).

[22] Vago, R., Marsden, C.J., Lord, J.M., Ippoliti, R., Flavell, D.J., Flavell, S.U., Ceriotti, A., and Fabbrini, M.S. "Saporin and Ricin A Chain Follow Different Intracellular Routes to Enter the Cytosol of Intoxicated Cells.” FEBS Journal 272(19), 4983-95 (2005).

[23] Lilletvedt, M., Tonnesen, H.H., Hogset, A., Nardo, L., and Kristensen, S. "Physicochemical Characterization of the Photosensitizers TPCS2a and TPPS2a 1. Spectroscopic Evaluation of Drug Solvent Interactions." Pharmazie 65(8), 588-95 (2010).

[24] Valeriote, F., and Lin, H.. "Synergistic Interaction of Anticancer Agents: A Cellular Perspective." Cancer Chemotherapy Reports Part 1 59(5), 895-900 (1975).

[25] Acedo, P., Stockert, J.C., Cañete, M., and Villanueva, A. "Two Combined Photosensitizers: A Goal for More Effective Photodynamic Therapy of Cancer." Cell Death and Disease 5(3), 1-12 (2014). 